\title{
Translation, reliability and validity of the job satisfaction scale in a sample of Portuguese fitness professionals
}

\author{
Liliana Ramos ${ }^{1,2,3}$ (D) $\cdot$ Dulce Esteves $^{3,4}$ (D) $\cdot$ Isabel Vieira ${ }^{1,2,3}$ (D) $\cdot$ Susana Franco ${ }^{1,2}$ (D) $\cdot$ Vera Simões $^{1,2}$ (I)
}

Accepted: 9 October 2020

(C) Springer Science+Business Media, LLC, part of Springer Nature 2020

\begin{abstract}
This study aimed to translate and validate the job satisfaction scale (JSS) to Portuguese fitness professionals. A total of 418 fitness professionals (210 male; 208 female) with an average age of $30.9 \pm 6.5$ years and a professional experience of $7.72 \pm 9.1$ years participated in this study. Before conducting a confirmatory factor analysis (CFA), we designed a test-retest analysis to determine reliability. Cronbach's alpha demonstrated satisfactory internal consistency (.96), which revealed a high degree of temporal reliability. The confirmatory analyses supported a unidimensional model ( 1 factor/ 16 item) of the JSS in terms of model adequacy coefficients. In conclusion, we found that the measurement model (1 factor/16 items) of the translation and validation of the JSS for Portuguese fitness professionals had highly acceptable psychometric properties and can be used in future to access their job satisfaction.
\end{abstract}

Keywords Job satisfaction $\cdot$ Job satisfaction scale $\cdot$ Fitness professionals $\cdot$ Validation studies $\cdot$ Psychometrics

\section{Introduction}

A certified fitness professional has substantial knowledge about exercise and health (Fischer \& Bryant, 2008) and encourages clients in their exercise routine to evaluate their fitness strengths and weaknesses, measures their physical exercise progress and educates them about wellness and health (Terason, 2018). In 2019, the Portugal Gyms Association reported that approximately 12,086 fitness professionals are working in the sector, leading to the substantial growth of this sector and contributing to customer satisfaction and retention (AGAP,

Electronic supplementary material The online version of this article (https://doi.org/10.1007/s12144-020-01116-1) contains supplementary material, which is available to authorized users.

Liliana Ramos

lilianaramos@esdrm.ipsantarem.pt

1 Sport Science School of Rio Maior, Polytechnic Institute of Santarém, Santarém, Portugal

2 Life Quality Research Centre, CIEQV, Santarém, Portugal

3 Department of Sports Sciences, University of Beira Interior UBI, Covilhã, Portugal

4 Research Centre in Sport, Health and Human Development, CIDESD, Vila Real, Portugal
2020). When fitness professionals are satisfied with their work, it contributes, as in other professions, to high organizational commitment and low turnover rate between jobs (Llorente \& Macías, 2005; Yousef, 2017).

Job satisfaction is frequently measured in industrial/ organizational psychology (Dormann \& Zapf, 2001; Heritage, Pollock, \& Roberts, 2015). Furthermore, such satisfaction is strongly related to optimal well-being (Sironi, 2019), mental and physical health (Faragher, Cass, \& Cooper, 2005), organizational commitment (Lok \& Crawford, 2004) and is moderately related to job performance (Judge, Thoresen, Bono, \& Patton, 2001). Higher levels of professional identity and job satisfaction are also associated with less burnout, and job satisfaction may perform a facilitating role between professional identity and burnout (Lu, Luo, Chen, \& Wang, 2019; Malinen \& Savolainen, 2016).

Job satisfaction includes the judgment of an individual's job or job circumstances, reflecting their reaction to the features, contests and profits of the work in which they are involved (Weiss, 2002). Thus, job satisfaction can be conceptualized as 'a related constellation of attitudes about various aspects or facets of the job' (Spector, 1997, p. 2).

The main aspects of job satisfaction have been defined as 'intrinsic'-reflecting the more internal reactions to integral structures of the work involved, such as the autonomy to carry out one's work process or the acknowledgement that one 
receives from performing good work - and 'extrinsic', which describes job features that are more external to the work involved, including salary, responsibility and autonomy, management structures and team relationships (Hills, Joyce, \& Humphreys, 2012; Spector, 2008; Stride, Wall, \& Catley, 2007; Warr, Cook, \& Wall, 1979). Research regarding job satisfaction is typically undertaken using self-report questionnaires in cross-sectional or longitudinal surveys. Besides that, several job satisfaction instruments, including single- and multi-item scales, have been employed over the last three decades (Hills et al., 2012).

\section{Job Satisfaction Scale}

The job satisfaction scale (JSS) is one of the most frequent questionnaires used in academic contexts. Several studies report the translation and validation of this instrument to different countries and employee types (Castañeda-Hidalgo et al., 2009; Heritage et al., 2015; Magnavita, Fileni, \& Bergamachi, 2009). However, the factorial structure underlying JSS and its psychometric properties are still under examination (Gonçalves, Santos, Orgambídez-Ramos, Nené \& Sousa, 2016;Heritage et al., 2015 ; Hills et al., 2012).

The original version of the JSS (Warr et al., 1979) divided employee satisfaction into the intrinsic and extrinsic factors required to accomplish job satisfaction. For this purpose, the authors proposed 15 quantitative items, which indicate the intrinsic/extrinsic factors and a 16th item measuring overall job satisfaction. All items reflect positive senses, and participants must indicate how satisfied or dissatisfied they are about each work characteristic. The response scale is from 1 (extremely dissatisfied) to 7 (extremely satisfied). The structure proposed by the original authors, after performing a preliminary cluster analysis (an exploratory technique), comprises two- (intrinsic/extrinsic) or three- (job itself intrinsic satisfaction/working conditions extrinsic satisfaction/ employee relations satisfaction) factor solutions.

Some authors (Heritage et al., 2015; Hills et al., 2012) have analyzed the JSS structure with more sophisticated statistical methods. Using exploratory factor analysis, several authors (Arias, Rivera, \& Ceballos, 2017; Boluarte, 2014; Falkum \& Vladum, 2005; Heritage et al., 2015; Hills et al., 2012; Morrison, 2004) have developed a single-factor solution that better represents the JSS structure. More recent studies cite the two-factor solution of the JSS provided by the original version, although these recent works were based on the cluster analysis technique (Ose et al., 2010; Solberg et al., 2012; Travers \& Cooper, 1993; Turner, Ross, \& Ibbetson, 2011), identical to the original authors' approach. The two-factor solution of the JSS was also analyzed in other countries, including Italy (Magnavita et al., 2009), the United Kingdom and Malaysia (Malek \& Flin, 2010). Short versions (Cooper, Rout, \& Faragher, 1989; Goetz et al., 2012) of the original JSS also seem to assume two-factor representativeness, based on the original exploratory findings; however, these versions do not provide statistical evidence to support this assumption. The three-factor solution, noted by the original authors, was also used by Ulleberg and Rundmo (1997), with a sample of 1137 employees on offshore oil installations in the Norwegian part of the North Sea. However, the 'working conditions extrinsic' factor had a low and unacceptable internal consistency $(a=.57)$, concurring with the original authors' findings.

\section{Present Study}

Currently, no instrument assesses fitness professionals' job satisfaction in Portugal. Regarding the JSS, some research has made contributions to the translation and validation of this instrument (Gonçalves et al., 2016), although the data comprised 632 participants from several jobs and not from a fixed career type. Gonçalves et al. (2016) supported the findings of a unidimensional solution (1 factor/16 item) best representative of the JSS in terms of internal consistency.

Considering the previous assumptions and the lack of instruments to assess job satisfaction in Portugal, specifically in the fitness area, this study aims to translate and investigate the factor structure, performing reliability and validity analyses of the JSS for the Portuguese population, more specifically for fitness professionals.

\section{Method}

\section{Instruments}

The JSS (Warr et al., 1979), in its original version, comprised 16 items divided by the original authors into two- or threefactor solutions (Table 1) for the first 15 items. The 16th item reported on overall job satisfaction. For the answers, a sevenpoint Likert scale was used, which varied between 1 (Extremely Dissatisfied) and 7 (Extremely Satisfied).

\section{Translation of Questionnaire}

Translation and adaption of the JSS from the original language (English) to Portuguese were carried out using methodological procedures recommended by Vallerand (1989). However, as an alternative to the translation/back-translation method, the committee approach was used. The procedure of translation/adaption was divided into five stages: (1) Initial Translation: the translation was completed by the investigators with the assistance of two professional translators, with academic education in English-Portuguese - 1st version of the questionnaire; (2) First Committee: examination of the 1st version by a group of four experts from different academic research areas (Sports Psychology, Sports Science, 
Table 1 Item factor of the JSS (Warr et al., 1979)

\begin{tabular}{|c|c|c|c|c|c|}
\hline \multirow[b]{2}{*}{ Item } & \multicolumn{2}{|c|}{ Two-factor solution } & \multicolumn{3}{|c|}{ Three-factor solution } \\
\hline & Intrinsic & Extrinsic & $\begin{array}{l}\text { Job Itself } \\
\text { intrinsic }\end{array}$ & $\begin{array}{l}\text { Working conditions } \\
\text { extrinsic }\end{array}$ & $\begin{array}{l}\text { Employee } \\
\text { relations }\end{array}$ \\
\hline $\begin{array}{l}\text { 1. Physical work } \\
\text { conditions }\end{array}$ & & $\mathrm{X}$ & & $X$ & \\
\hline 2. Method of working & $X$ & & $\mathrm{X}$ & & \\
\hline 3. Fellow workers & & $X$ & & $\mathrm{X}$ & \\
\hline 4. Recognition & $X$ & & & & $\mathrm{X}$ \\
\hline 5. Immediate boss & & $X$ & & $\mathrm{X}$ & \\
\hline 6. Responsibility & $\mathrm{X}$ & & $\mathrm{X}$ & & \\
\hline 7. Pay & & $X$ & & & $\mathrm{X}$ \\
\hline 8. Abilities & $\mathrm{X}$ & & $\mathrm{X}$ & & \\
\hline 9. Industrial Relations & & $X$ & & & $\mathrm{X}$ \\
\hline 10. Promotion & $\mathrm{X}$ & & & & $\mathrm{X}$ \\
\hline 11. Management & & $X$ & & & $\mathrm{X}$ \\
\hline 12. Suggestions & $\mathrm{X}$ & & & & $\mathrm{X}$ \\
\hline 13. Hours & & $X$ & & $\mathrm{X}$ & \\
\hline 14. Variety & $\mathrm{X}$ & & $\mathrm{X}$ & & \\
\hline 15. Job security & & $\mathrm{X}$ & & $X$ & \\
\hline $\begin{array}{l}\text { 16. Overall job } \\
\text { satisfaction }\end{array}$ & & & & & \\
\hline
\end{tabular}

Psychology, Fitness Professionals) that resulted in the 2nd version of the questionnaire; (3) Second Committee: the second version was given to a new panel of 4 specialists (Sports Science, Sports Psychology, Fitness Professionals) who analyzed and decided unanimously upon the questionnaire item contents, resulting in the 3rd version of the questionnaire; (4) A Pilot study was conducted with the 3 rd version of the questionnaire and was applied to 50 subjects (fitness higher education students) to determine issues related to understanding and clarification of the items. After this step, the 4th version resulted; (5) Final Review: a review of syntax aspects of the 4 th version by Portuguese teachers and elaboration of the final version.

\section{Participants}

Data collection involved 418 fitness professionals (males = 210 females $=208$ ) with an average age of $30.9 \pm 6.57$ (mean $(\mathrm{M}) \pm$ standard deviation (SD)) years and a professional experience of $7.72 \pm 9.1(\mathrm{M} \pm \mathrm{SD})$ years. $62.7 \%$ of the sample had a bachelor's degree, $23.9 \%$ a master's degree (MSc), $12 \%$ had completed secondary school, $1.2 \%$ held a $\mathrm{PhD}$, and $0.2 \%$ had a basic school education.

\section{Data Collection}

The questionnaires were applied using the SurveyMonkey platform, with a mean time for completion of $4 \mathrm{~min}$. Ethical approval was obtained from the ethics and scientific board of the University of Beira-Interior, Portugal.

\section{Statistical Analysis}

The data collected were analyzed using SPSS software (version 22.0). The mean (M) and standard deviation (SD) of each JSS item were determined. A preliminary analysis was conducted to verify data distribution, missing values and outliers. We performed a test-retest analysis to determine the reliability of the JSS before conducting a confirmatory factor analysis (CFA). Pearson's r coefficient was used to determine the testrest reliability of participant responses. Fifty participants were involved in this analysis, based on Hair, Black, Babin, and Anderson (2019) suggestions. The period between survey administrations was 4 weeks, as recommended by Vallerand (1989). A confirmatory factor analysis with a maximum likelihood method $(m l)$ in AMOS (version 23.0) was also performed. A proportion of at least 10:1 (ten subjects by parameter) was followed (Byrne, 2016) by a final sample of 418 subjects $($ males $=210$ females $=208$ ). The model adequacy was tested through the incremental and absolute indexes (Byrne, 2016; Hair et al., 2019), namely: the comparative fit index (CFI), the Tucker-Lewis index (TLI), the standard mean root square residual (SRMR) and the root mean square error of approximation (RMSEA) and its confidence interval $(90 \%$ CI). The following cut-off values were assumed: CFI and $\mathrm{TLI} \geq 0.90, \mathrm{SRMR} \leq 0.8$ and $\mathrm{RMSEA} \leq 0.8$. For the 
comparison of nested-models, a parsimony comparative fitindex was used, and cut-off values close to .08 were considered more parsimonious (Hair et al., 2019). Internal consistency, via composite reliability, was calculated, and values superior or equal to .70 were considered acceptable (Hair et al., 2019). Finally, average variance extracted (AVE) was also calculated to verify convergent validity (Hair et al., 2019), and values greater than or equal to .50 were assumed as the cut-off value, as recommended by Hair et al. (2019).

\section{Results}

\section{Preliminary Analysis}

There were no missing values, neither were there outliers or uni- or multivariate. Item-level descriptive statistics exposed no violations of a univariate normal distribution, since skewness and kurtosis were contained between -2 to +2 , and -7 to +7 , respectively (Byrne, 2016). However, the Mardia coefficient of Multivariate Kurtosis exceeded the recommended value (5.0); hence, a Bollen-Stine bootstrap (2000) was used for further analysis (Nevitt \& Hancock, 2001).

\section{Descriptive Statistics}

The values in Table 2 show the average, standard deviation, minimum and maximum of each JSS item. The highest values were from item 2 (5.93), referring to 'freedom to choose your working method', whereas item 10 (referring to 'your promotion opportunities') had the lowest values (4.54).

Table 2 Descriptive statistics

\begin{tabular}{ll}
\hline Job Satisfaction $n=418$ & \\
\hline Item $1 \mathrm{M} \pm \mathrm{SD}$ & $5.43 \pm 1.05$ \\
Item $2 \mathrm{M} \pm \mathrm{SD}$ & $5.93 \pm 1.10$ \\
Item $3 \mathrm{M} \pm \mathrm{SD}$ & $5.68 \pm 1.10$ \\
Item $4 \mathrm{M} \pm \mathrm{SD}$ & $5.06 \pm 1.46$ \\
Item $5 \mathrm{M} \pm \mathrm{SD}$ & $5.39 \pm 1.33$ \\
Item $6 \mathrm{M} \pm \mathrm{SD}$ & $5.47 \pm 1.15$ \\
Item $7 \mathrm{M} \pm \mathrm{SD}$ & $4.67 \pm 1.49$ \\
Item $8 \mathrm{M} \pm \mathrm{SD}$ & $5.65 \pm 1.10$ \\
Item $9 \mathrm{M} \pm \mathrm{SD}$ & $5.33 \pm 1.39$ \\
Item $10 \mathrm{M} \pm \mathrm{SD}$ & $4.54 \pm 1.58$ \\
Item $11 \mathrm{M} \pm \mathrm{SD}$ & $4.94 \pm 1.42$ \\
Item $12 \mathrm{M} \pm \mathrm{SD}$ & $4.97 \pm 1.34$ \\
Item $13 \mathrm{M} \pm \mathrm{SD}$ & $5.10 \pm 1.35$ \\
Item $14 \mathrm{M} \pm \mathrm{SD}$ & $5.37 \pm 1.16$ \\
Item $15 \mathrm{M} \pm \mathrm{SD}$ & $4.73 \pm 1.69$ \\
Item $16 \mathrm{M} \pm \mathrm{SD}$ & $5.44 \pm 1.11$ \\
\hline
\end{tabular}

\section{Test-Retest Analysis}

Bivariate Pearson's correlation revealed that responses to each item in the first and second surveys varied from .70 (item 9) to .97 (item 4). Additionally, Cronbach's alpha revealed an adequate internal consistency in two times (Table 3).

\section{Construct Validity}

Results from Table 4 show that the following models fit the data: Global model 1 factor with 16 items, a 3-Dimensional model with 3 factors and 15 items (without item 16), Hierarchical model with 3 factors and 14 items (without item 3/16) and Hierarchical model with 3 factors and 15 items (without item 16), according to the cut-off values adopted in the methodology (Byrne, 2016; Hair et al., 2019). The remaining models did not fit the data. The Global model 1 factor and 16 items were also more parsimonious compared to the others, suggesting that a one-dimensional solution was the best representative of the scale in Portuguese fitness professionals.

\section{Discussion}

The present study aimed to translate and validate the JSS to Portuguese fitness professionals. We also examined the JSS factor structure (Warr et al., 1979) through confirmatory factor analysis (CFA).

The results of translation and reliability showed adequate internal consistency in two times, resulting in a high degree of temporal reliability. The reliability value for all items was .96. In the only study contributing to the translation and validation of the JSS to the Portuguese language (Gonçalves et al., 2016), the scale reliability analysis was performed and obtained a value of .93, which also reveals an adequate consistency.

For the translation of the JSS into the original English version, some terms were changed in the process of translating the questionnaire, namely those related to 'industrial relations', which are highly specific to industry workers to which the original questionnaire was applied. There were also smallscale differences in our investigation and that of Gonçalves et al. (2016) that had been proposed by experts contributing to this methodological step. The term 'company' was exchanged for the term 'organization', which is most frequently used today in the fitness area. The final version of the JSS in Portuguese appears in Appendix 1.

Concerning the JSS factor structure, the original authors found two- (intrinsic/extrinsic) or three- (job itself intrinsic satisfaction/working conditions extrinsic satisfaction/ employee relations satisfaction) factor solutions that best represent JSS. These results were supported by a preliminary cluster analysis technique and an internal consistency that reveals, in the two studies that they were carried out in, less 
Table 3 Test-retest analysis

\begin{tabular}{llllll}
\hline Items & $\mathrm{M} \pm \mathrm{SD} 1$ & $\mathrm{M} \pm \mathrm{SD} 2$ & $r$ & Alpha \\
\hline Item 1 Pre-Post & $5.70 \pm 1.27$ & $5.76 \pm 1.02$ & .75 & $<.001$ \\
Item 2 Pre-Post & $5.76 \pm 1.19$ & $5.72 \pm 1.14$ & .91 & $<.001$ \\
Item 3 Pre-Post & $6.10 \pm 1.04$ & $5.96 \pm 1.16$ & .80 & $<.001$ \\
Item 4 Pre-Post & $5.27 \pm 1.43$ & $5.22 \pm 1.39$ & .97 & $<.001$ \\
Item 5 Pre-Post & $5.38 \pm 1.44$ & $5.44 \pm 1.26$ & .93 & $<.001$ \\
Item 6 Pre-Post & $5.56 \pm 1.16$ & $5.54 \pm 1.28$ & .83 & $<.001$ \\
Item 7 Pre-Post & $4.76 \pm 1.48$ & $4.90 \pm 1.23$ & .78 & $<.001$ \\
Item 8 Pre-Post & $5.48 \pm 1.18$ & $5.42 \pm 1.26$ & .92 & $<.001$ \\
Item 9 Pre-Post & $5.52 \pm 1.23$ & $5.30 \pm 1.40$ & $.70<.001$ \\
Item 10 Pre-Post & $5.20 \pm 1.53$ & $5.00 \pm 1.51$ & .90 & $<.001$ \\
Item 11 Pre-Post & $5.30 \pm 1.43$ & $5.26 \pm 1.50$ & .94 & $<.001$ \\
Item 12 Pre-Post & $5.48 \pm 1.25$ & $5.32 \pm 1.20$ & .86 & $<.001$ \\
Item 13 Pre-Post & $4.94 \pm 1.45$ & $4.82 \pm 1.45$ & .89 & $<.001$ \\
Item 14 Pre-Post & $5.46 \pm 1.25$ & $5.48 \pm 1.25$ & .92 & $<.001$ \\
Item 15 Pre-Post & $5.38 \pm 1.43$ & $5.34 \pm 1.49$ & .92 & $<.001$ \\
Item 16 Pre-Post & $5.56 \pm 1.07$ & $5.54 \pm 1.05$ & .94 & $<.001$ \\
Job Satisfaction & $5.42 \pm 1.03$ & $5.38 \pm 1.02$ & $.98<.001$ & .96 \\
Pre-Post & & & & \\
\hline
\end{tabular}

acceptable alpha reliability for the working conditions' extrinsic satisfaction factor ( $a=.58$ to .60 ); therefore, they proposed the use of two-factor solutions (intrinsic/extrinsic). The current did not support those findings. The Global model 1 factor/ 16 items, 3-Dimensional model 3 factors/15items,
Hierarchical model 3 factors/14items (without items 3/16) and Hierarchical model of 3 factors/15items (without item 16) provided the best model fit. However, the low parsimony comparative fit-index of these models revealed that Global model 1 factor/ 16 items were considered more parsimonious than the others. Item 3, relating to 'Fellow workers' and item 13 , 'Hours of work', were the weakest of the JSS items in terms of its relatedness to latent factors. However, they do not impact the internal reliability when omitted; hence, it is not reasonable to suggest that these items should be omitted when using the JSS for Portuguese fitness professionals.

Over the decades, several authors have translated and validated the JSS to other languages and/or analyzed the scale's factor structure, exploring more advanced statistical techniques than the original authors. Heritage et al. (2015), using confirmatory factor analyses, tested several models, and the results supported a Hierarchical three-factor model of job satisfaction in terms of model adequacy coefficients. However, the three factors were highly correlated, so they recommended the use of the JSS as a total score, corroborating the results of our study, although the Global JSS model of these authors comprises 1 factor/15 item (without item 16), and our results reveal better parsimony in the Global model 1 factor/ 16 items. Arias et al. (2017) performed an exploratory and confirmatory factor analysis and confirmed that the JSS has a better adjustment in a Global model 1 factor/15 items (without item 16), similar to Heritage and co-workers' (Heritage et al., 2015) findings. Gonçalves et al. (2016), who also translated and

Table 4 Fit indexes of the measurement models

\begin{tabular}{|c|c|c|c|c|c|c|c|c|c|c|c|}
\hline Models & $\mathrm{X}^{2}$ & df & $\mathrm{X}^{2} / \mathrm{dt}$ & B-S p & CFI & TLI & SRMR & RMSEA-90\% & PCFI & AVE & $\mathrm{CR}$ \\
\hline $\begin{array}{l}\text { Global Model } \\
1 \mathrm{~F} / 16 \text { items }\end{array}$ & 418.002 & 104 & 4.019 & $<.001$ & .914 & .901 & .0449 & $.080(.077-.094)$ & .792 & .48 & .93 \\
\hline $\begin{array}{l}\text { Global Model } \\
1 \mathrm{~F} / 15 \text { items } \\
\text { (without } 16 \text { ) }\end{array}$ & 361.136 & 90 & 4.013 & $<.001$ & .89 & .814 & .463 & $.080(.076-.094)$ & .783 & .43 & .93 \\
\hline $\begin{array}{l}\text { Bi-Dimensional } \\
\text { 2F/15 items } \\
\text { (without } 16 \text { ) }\end{array}$ & 357.551 & 89 & 4.017 & $<.001$ & .915 & .899 & .0461 & $.080(.076-.094)$ & .775 & $1 \mid .40$ & $.880 \mid .847$ \\
\hline $\begin{array}{l}\text { 3-Dimensional } \\
\text { 3F/15 items } \\
\text { (without } 16 \text { ) }\end{array}$ & 317.900 & 87 & 3.654 & $<.001$ & .927 & .911 & .0436 & $.080(.070-.089)$ & .768 & $.51|.31| .59$ & .804|.690|.896 \\
\hline $\begin{array}{l}\text { Hierarchical Model } \\
2 \mathrm{~F} / 15 \text { items } \\
\text { (without } 16 \text { ) }\end{array}$ & 935.078 & 90 & 10.834 & $<.001$ & .718 & .671 & .0226 & $.080(.145-.162)$ & .616 & $.62 \mid .53$ & $.918 \mid .896$ \\
\hline $\begin{array}{l}\text { Hierarchical Model } \\
2 \mathrm{~F} / 14 \text { items } \\
\text { (without } 13 / 16 \text { ) }\end{array}$ & 895.865 & 77 & 11.635 & $<.001$ & .723 & .673 & .2309 & $.160(.150-.169)$ & .612 & $.61 \mid .55$ & $.918 \mid .892$ \\
\hline $\begin{array}{l}\text { Hierarchical Model } \\
3 \mathrm{~F} / 14 \text { items } \\
\text { (without } 3 / 16 \text { ) }\end{array}$ & 266.471 & 74 & 3.601 & $<.001$ & .936 & .922 & .0410 & $.080(.069-.089)$ & .761 & $.50|.33| .59$ & .803|.659|.896 \\
\hline $\begin{array}{l}\text { Hierarchical Model } \\
3 \mathrm{~F} / 15 \text { items } \\
\text { (without } 16 \text { ) }\end{array}$ & 317.900 & 87 & 3.654 & $<.001$ & .927 & .911 & .0436 & $.080(0.70-0.89)$ & .768 & $.50|.31| .59$ & .804|.690|.896 \\
\hline
\end{tabular}


validated the JSS into Portuguese, support the use of a general factor of job satisfaction (1 factor/16 item). Morrison (2004) carried out a confirmatory factor analysis indicating that the items constituting the JSS could be analyzed in one dimension, with a coefficient of .83. In the test-retest analysis, a coefficient of .63 was obtained for total job satisfaction. The authors recommended using only one dimension.

This version of the JSS for Portuguese fitness professionals allows us to measure these professionals' job satisfaction and compare the scores achieved with other variables and with other countries' fitness professionals. In Spain, the JSS version translated and validated for Spanish by Boluarte (2014) was used to measure job satisfaction of fitness professionals with a degree in physical activity and sports science as well to compare job satisfaction with five professional profiles (Grimaldi-Puyana, Pérez-Villalba, Bernal-Garcia, \& Sânchez-Oliver, 2018). Also in Spain, a comparative study across age, gender, work experience and higher degree studied was performed with fitness professionals (Bernabé, GonzálezRivera, \& Campos-Izquierdo, 2016). Other works (Koehler 1998; Koustelios, Kouli, \& Theodorakis, 2003; Bevilacqua, Silva, Reichert \& Rombaldi 2014) measured job satisfaction for fitness professionals in different countries, using other instruments.

With the substantial growth of gyms and consequent increases in fitness professional numbers in Portugal, this questionnaire may represent an important tool for measuring job satisfaction of these professionals, and it may be vital for retention and satisfaction of fitness service consumers.

\section{Conclusions}

We found that the model (1 factor/16 item) of the translation and validation of the JSS (Warr et al., 1979) for Portuguese fitness professionals had highly acceptable psychometric properties and can be used in this manner to measure their job satisfaction.

However, the instruments' validation is a lengthy process, and more studies are necessary to support our findings. More robust psychometric techniques (e.g., invariance analyses of this measurement model with other variables or cultures) should be explored, studies with this scale should be carried out for other professions, and because this was a crosssectional study, a longitudinal analysis should be conducted.

Finally, it must be emphasized that this research not only involved a Portuguese version of the JSS for fitness professionals, filling a gap that had existed, but it also provided an instrument to allow fitness professionals associations, fitness managers and fitness directors to acquire valid and reliable indicators of fitness professionals' job satisfaction. Hence, this work identified why professionals are dissatisfied and may be attempting to improve their working conditions and, therefore, provide a better service for fitness customers.

Funding Portuguese Foundation for Science and Technology, I.P., Grant/Award Number UIDP/04748/2020.

Data Availability Nothing to declare.

\section{Compliance with Ethical Standards}

Conflict of Interest On behalf of all authors, the corresponding author states that there is no conflict of interest.

Ethical Statement The research protocol was approved by the Ethics Committee of the University of Beira Interior, Portugal ( ${ }^{\circ}$ ID1126).

Ethics, Consent and Permissions The purposes of the study and the ethical consideration for the participants (e.g., confidentiality of their information and management of data anonymously) were explained to the participants. All participants had given informed consent to be included in the study.

Code Availability Nothing to declare.

\section{References}

AGAP. (2020). Barómetro do Fitness 2019. Lisboa: Edições AGAP.

Arias, W., Rivera, R., \& Ceballos, K. (2017). Análisis psicométrico de la Escala de Satisfacción Laboral de Warr, Cook y Wall en una muestra multiocupacional de Arequipa, Perú. Interacciones, 3(2), 79-85. https://doi.org/10.24016/2017.v3n2.74.

Bernabé, B., González-Rivera, M. D., \& Campos-Izquierdo, A. (2016). Job satisfaction of sport and physical activity instructors in Spain according to gender and age. South African Journal for Research in Sport, Physical education and Recreation, 38(1), 1-12.

Bevilacqua, L., Silva, M., Reichert, F., Rombaldi, A. (2014) Qualidade de vida e satisfação com o trabalho de profissionais das academias de ginástica da cidade de Pelotas/RS. Revista Brasileira de Atividade Física \& Saúde, 19(3), 314-324. https://doi.org/10.12820/rbafs.v. $19 \mathrm{n} 3 \mathrm{p} 314$

Boluarte, A. (2014). Propiedades psicométricas de la Escala de satisfacción laboral de Warr, Cook y Wall, versión en español. Rev. Med. Hered, 25, 80-84. https://doi.org/10.20453/rnp.2014. 249.

Byrne, B. (2016). Structural equation modeling with AMOS: Basic concepts. Applications and programming (3rd ed.). New York: Routledge.

Castañeda-Hidalgo, H., Acevedo, G., Garza, R., Meléndez, C., Rangel, S., \& Aguilera, A. (2009). Translation and adaptation of an instrument to measure nurse job satisfaction. HHCI, 7(3), 116-122. https://doi.org/10.1891/1540-4153.7.3.116.

Cooper, C. L., Rout, U., \& Faragher, B. (1989). Mental health, job satisfaction, and stress among general practitioners. BMJ, 298, 366-370.

Dormann, C., \& Zapf, D. (2001). Job satisfaction: A meta-analysis of stabilities. Journal of Organizational Behavior, 22, 483-504. https://doi.org/10.1002/job.98.

Falkum, E., \& Vladum, P. (2005). The relationship between interpersonal problems and occupational stress in physicians. General Hospital Psychiatry, 27(4), 285-291. https://doi.org/10.1016/j. genhosppsych.2005.03.006. 
Faragher, E. B., Cass, M., \& Cooper, C. L. (2005). The relationship between job satisfaction and health: A meta-analysis. Oсcup. and Environ. Med, 62(2), 105-112. https://doi.org/10.1136/OEM.2002. 006734.

Fischer, D. V., \& Bryant, J. (2008). Effect of certified personal trainer services on stage of exercise behavior and exercise mediators in female college students. Journal of American College Health, 56, 369-376. https://doi.org/10.3200/JACH.56.44.369-376.

Goetz, K., Campbell, S. M., Broge, B., Dorfer, C. E., Brodowski, M., \& Szecsenyi, J. (2012). The impact of intrinsic and extrinsic factors on the job satisfaction of dentists. Community Dent Oral, 40(5), 474 480. https://doi.org/10.1111/j.1600-0528.2012.00693.x.

Gonçalves, G., Santos, J., Orgambídez-Ramos, A., Nené D., \& Sousa, C. (2016). Contributos para a adaptação para a população Portuguesa da Escala de Satisfação Profissional de Warr, Cook e Wall (1979). Forum on Management Global Industries: The Role of Hospitality and Tourism, organizado pela Escola Superior de Hotelaria e Turismo do Estoril, Universidade Aberta e Escola Superior de Gestão, Hotelaria e Turismo (UAlg), Estoril 10-11-2016.

Grimaldi-Puyana, M., Pérez-Villalba, M., Bernal-Garcia, A., \& SânchezOliver, A. J. (2018). Comparative study of job satisfaction in workers with a degree in physical activity and sports science. Journal of Physical Education and Sport, 18(204), 1380-1385. https://doi.org/10.7752/jpes.2018.s3204

Hair, J. F., Black, W. C., Babin, B. J., \& Anderson, R. E. (2019). Multivariate data analysis (8rd ed.). Boston: Cengage.

Heritage, B., Pollock, C., \& Roberts, L. D. (2015). Confirmatory factor analysis of Warr, Cook, and Wall's (1979) job satisfaction scale. Australian Psychologist, 50(2015), 122-129. https://doi.org/10. 1111/ap.12103.

Hills, D., Joyce, C., \& Humphreys, J. (2012). Validation of a satisfaction scale in the Australian clinical medical workforce. Evaluation \& the Health Professions, 35(1), 47-76. https://doi.org/10.1177/ 0163278710397339.

Judge, T. A., Thoresen, C. J., Bono, J. E., \& Patton, G. K. (2001). The job satisfaction-job performance relationship - A qualitative and quantitative review. Psychological Bulletin, 127(3), 376-407. https://doi. org/10.1037/0033-2909.127.3.376.

Koehler, L. (1988). Job Satisfaction and Corporate Fitness Managers: An organizational behavior approach to sport management. Journal of Sport Management, 2, 100-105.

Koustelios, A., Kouli, O., \& Theodorakis, N. (2003). Job security and job satisfaction among Greek fitness instructors. Perceptual and Motor Skills, 97, 192-194.

Llorente, R., \& Macías, E. (2005). Job satisfaction as an indicator of the quality of work. The Journal of Socio-Economics, 34(5), 656-673. https://doi.org/10.1016/j.socec.2005.07.027.

Lok, P., \& Crawford, J. (2004). The effect of organizational culture and leadership style on job satisfaction and organizational commitement: A cross-national comparison. Journal of Management Development, 23(4), 321-338. https://doi.org/10.1108/ 02621710410529785 .

Lu, M., Luo, J., Chen, W., \& Wang, M. C. (2019). The influence of job satisfaction on the relationship between professional identity and burnout: A study of student teachers in Western China. Current Psychology. https://doi.org/10.1007/s12144-019-00565-7.

Magnavita, N., Fileni, A., \& Bergamachi, A. (2009). Satisfaction at work among radiologists. La Radiologia Medica, 114, 1330-1344. https://doi.org/10.1007/s11547-009-0461-z.

Malek, M., \& Flin, K. (2010). Stress and psychological well-being in UK and Malaysian fire fighters. The International Journal of Cross Cultural Management, 17(1), 50-61. https://doi.org/10.1108/ 135276010110169

Malinen, O., \& Savolainen, H. (2016). The effect of perceived school climate and teacher efficacy in behavior management on job satisfaction and burnout: A longitudinal study. Teaching and Teacher Education, 60, 144-152. https://doi.org/10.1016/j.tate. 2016.08.012.

Morrison, R. (2004). Informal relationships in the workplace: Associations with job satisfaction, organizational commitment and turnover intentions. New Zealand Journal of Psychology, 33(3), 114-128.

Nevitt, J., \& Hancock, G. R. (2001). Performance of bootstrapping approaches to model test statistics and parameter standard error estimation in structural equation modeling. Structural Equation Modeling, 8(3), 353-377. https://doi.org/10.1207/ S15328007SEM0803-3.

Ose, D., Freund, T., Kunz, C. U., Szecsenyi, J., Natanzon, I., Trieschmann, J., \& Miksch, A. (2010). Measuring organizational attributes in primary care: A validation study in Germany. Journal of Evaluation in Clinical Practice, 16(6), 1289-1294. https://doi. org/10.1111/j.1365-2753.2009.01330.x.

Sironi, E. (2019). Job satisfaction as a determinant of employees' optimal well-being in an instrumental variable approach. Qual Quant, 53(4), 1721-1742. https://doi.org/10.1007/s11135-019-00835-3.

Solberg, I. B., Rø, K. I., Aasland, O., Gude, T., Moum, T., Vaglum, P., \& Tyssen, R. (2012). The impact of change in a doctor's job position: A five-year cohort study of job satisfaction among Norwegian doctors. BMC Health Services Research, 12(41), 1-7. https://doi.org/ 10.1186/1472-6963-12-41.

Spector, P. E. (1997). Job satisfaction: Application, assessment, causes and consequences. Thousand Oaks, C.A: SAGE.

Spector, P.E. (2008). Industrial and organizational psychology: Research and practice. Hoboken: NJ.

Stride, C., Wall, T. D., \& Catley, N. (2007). Measures of job satisfaction, organizational commitment, mental health and job-related well-being: A benchmarking manual (2nd ed.). Chichester, UK: John Wiley.

Terason, S. (2018). The influence of job autonomy on job satisfaction in Thai fitness trainer professionals: A moderation analysis. Journal of Entrepreneurship \& Organization Management, 7(1), 225. https:// doi.org/10.4172/2169-026X.1000225.

Travers, C. J., \& Cooper, C. L. (1993). Mental health, job satisfaction and occupational stress among UK teachers. Work and Stress, 7, 203 219. https://doi.org/10.1080/02678379308257062.

Turner, S., Ross, M. K., \& Ibbetson, R. J. (2011). Job satisfaction among dually qualified dental hygienist-therapists in UK primary care: A structural model. British Dental Journal, 210(4), 1-7. https://doi. org/10.1038/sj.bdj.2011.50.

Ulleberg, P., \& Rundmo, T. (1997). Job stress, social support, job satisfaction and absenteeism among offshore oil personnel. Work and Stress, 11(3), 215-228. https://doi.org/10.1080/ 02678379708256836 .

Vallerand, R. J. (1989). Toward a methodology for the transcultural validation of psychological questionnaires: Implications for research in the French language. Canadian Psychologist, 30(4), 662-680. https://doi.org/10.1037/h0079856.

Warr, P., Cook, J., \& Wall, T. (1979). Scales for the measurement of some work attitudes and aspects of psychological well-being. Journal of Occupational Psychology, 52, 129-148.

Weiss, H. M. (2002). Deconstructing job satisfaction: Separating evaluations, beliefs and affective experiences. Human Resour Manage $R$, 12(2002), 173-194. https://doi.org/10.1016/S1053-4822(02)000451 .

Yousef, D. (2017). Organizational commitment, job satisfaction and attitudes toward organizational change: A study in the local government. International Journal of Public Administration, 40(1), 77-88. https://doi.org/10.1080/01900692.2015.1072217.

Publisher's Note Springer Nature remains neutral with regard to jurisdictional claims in published maps and institutional affiliations. 